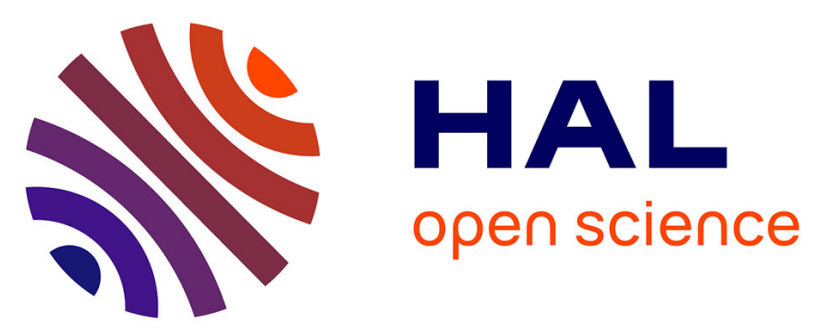

\title{
Analogues of the 2-carboxyl-6-hydroxyoctahydroindole (CHOI) unit from diverging Pd-catalyzed allylations: Selectivity as a function of the double bond position
} Zhongyi Mao, Elisabetta Martini, Guillaume Prestat, Julie Oble, Pei-Qiang Huang, Giovanni Poli

\section{To cite this version:}

Zhongyi Mao, Elisabetta Martini, Guillaume Prestat, Julie Oble, Pei-Qiang Huang, et al.. Analogues of the 2-carboxyl-6-hydroxyoctahydroindole (CHOI) unit from diverging Pd-catalyzed allylations: Selectivity as a function of the double bond position. Tetrahedron Letters, 2017, 58 (44), pp.4174-4178. 10.1016/j.tetlet.2017.09.046 . hal-01675514

\section{HAL Id: hal-01675514 \\ https://hal.sorbonne-universite.fr/hal-01675514}

Submitted on 4 Jan 2018

HAL is a multi-disciplinary open access archive for the deposit and dissemination of scientific research documents, whether they are published or not. The documents may come from teaching and research institutions in France or abroad, or from public or private research centers.
L'archive ouverte pluridisciplinaire HAL, est destinée au dépôt et à la diffusion de documents scientifiques de niveau recherche, publiés ou non, émanant des établissements d'enseignement et de recherche français ou étrangers, des laboratoires publics ou privés. 


\title{
Analogues of the 2-Carboxyl-6-Hydroxyoctahydroindole (CHOI) Unit from Diverging Pd-Catalyzed Allylations: Selectivity as a Function of the Double Bond Position
}

\author{
Zhongyi Mao, ${ }^{\text {a,b }}$ Elisabetta Martini, ${ }^{\text {a }}$ Guillaume Prestat, ${ }^{\text {a, }}$ Julie Oble, ${ }^{\mathrm{a}, *}$ Pei-Qiang Huang, ${ }^{\text {b, }}$ and Giovanni \\ Poli $^{\mathrm{a}, *}$ \\ ${ }^{a}$ Sorbonne Universités, UPMC Univ Paris 06, CNRS, Institut Parisien de Chimie Moléculaire (IPCM), UMR 8232, 4 place Jussieu, 75005 Paris, France. \\ ${ }^{b}$ Department of Chemistry and Key Laboratory for Chemical Biology of Fujian Province, College of Chemistry and Chemical Engineering, Xiamen University, \\ Fujian 361005, P. R. China
}

\section{ARTICLE INFO}

Article history:

Received

Received in revised form

Accepted

Available online

Keywords:

Palladium catalysis

CHOI core

allylic substitution

domino reaction

stereoselective synthesis

\section{ABSTRACT}

Pd-catalyzed allylations of cyclic bis-allylic substrates, carried out either as two separate steps or in a pseudo-domino fashion, can generate 2-carboxyl-hexahydroindoles bearing an unsaturation in different positions. Sequential homologation, and epoxidation or syn-dihydroxylation steps were investigated to access analogues of the bicyclic 2-carboxyl-6-hydroxyoctahydroindole motif of aeruginosins, a family of peptides displaying serine protease inhibitor activity..

\section{Introduction}

Aeruginosins ${ }^{1}$ constitute a family of structurally related molecules found in cyanobacteria (blue-green algae). These peptidic structures that incorporate the 2-carboxyl-6 $\alpha$-hydroxyoctahydroindole (CHOI) bicyclic structure hydroxylated in 5 and / or 6 positions, display inhibitory actions against several serine proteases such as thrombin and trypsin (Figure 1). ${ }^{2}$ Since the discovery of their potent anticoagulant action, structure-activity relationship (SAR) studies on aeruginosin family are constantly and intensively pursued. ${ }^{3}$ Although synthetic routes of some of these structures have been recently reported, further studies are still desirable, especially those focusing on the common bicyclic CHOI fragment and access to analogues of it.

Some years ago, we anticipated that analogues of the CHOI motif could be ideal targets, achievable through palladium chemistry developed in our laboratory. ${ }^{4,5}$ In the present study we developed a double Pd-catalyzed allylation (amination and alkylation) of the cyclic bis-allylic substrate $\mathbf{I}$, which, as a function of the modus operandi, provided the desired bicyclic advanced intermediates II and III that differ by the double bond location (Scheme 1). After an appropriate one-carbon homologation at position 2, diastereoselective postfunctionalizations (epoxidation and syn-dihydroxylation) of the resulting hexahydroindoles IV and $\mathbf{V}$ were carried out to evaluate the selectivity of these transformations, which provide CHOI analogues as a function of the transformation and the position of the unsaturation.

\section{Results and discussion}

"Separated allylations" strategy-based approach to the bicyclic tetrahydroindolone 6 .

This strategy is based on the construction of the bicyclic tetrahydroindolone structure $\mathbf{6}$ starting from 1,3-cyclohexadiene 1. This was achieved through a five-step sequence (Scheme 2), as previously described by us. ${ }^{4 \mathrm{~b}}$ Two key steps of this synthetic sequence are based on palladium catalysis. First, 1,3cyclohexadiene $\mathbf{1}$ was converted into the corresponding chloroacetate cis-2 according to Bäckvall's protocol. ${ }^{6}$ Then, palladium-catalyzed allylation of $p$-methoxybenzylamine with the allylic chloride cis-2 afforded cis-3. Standard treatment of this amine with methyl 3-chloro-3-oxopropionate gave the 1,4disubstituted amide cis-4, which underwent a smooth intramolecular allylic alkylation. Two different palladium-based catalytic systems can be used, both leading to bicyclic lactam $\mathbf{5}$ in $80 \%$ as a single diastereoisomer. ${ }^{7}$ Finally, demethoxycarbonylation of $\mathbf{5}$ under Krapcho conditions ${ }^{8}$ led to lactam 6.

\footnotetext{
* Corresponding author. Tel.: +33-144-274-114; e-mail: julie.oble@upmc.fr; Tel.: +86-592-218-2240; e-mail: pqhuang@xmu.edu.cn;

* Corresponding author. Tel.: +33-144-274-114; e-mail: giovanni.poli@upmc.fr
} 


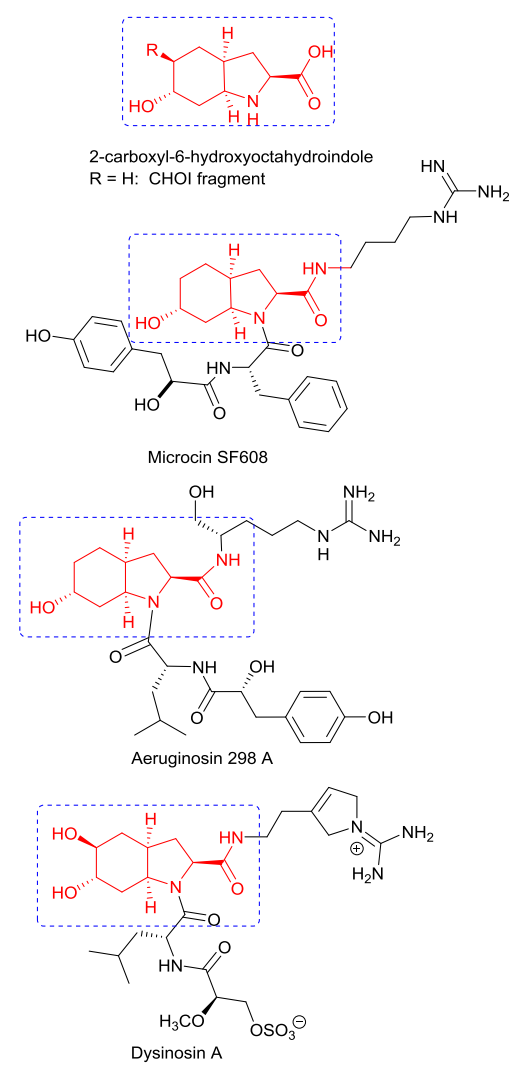

Figure 1. CHOI motif and representative members of the Aeruginosin family.

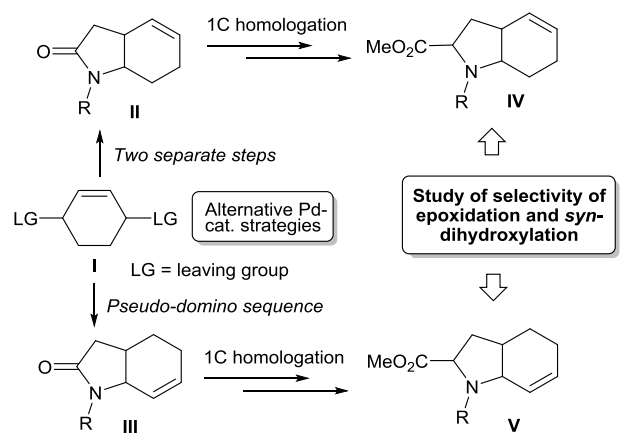

Scheme 1. CHOI aim of the project.
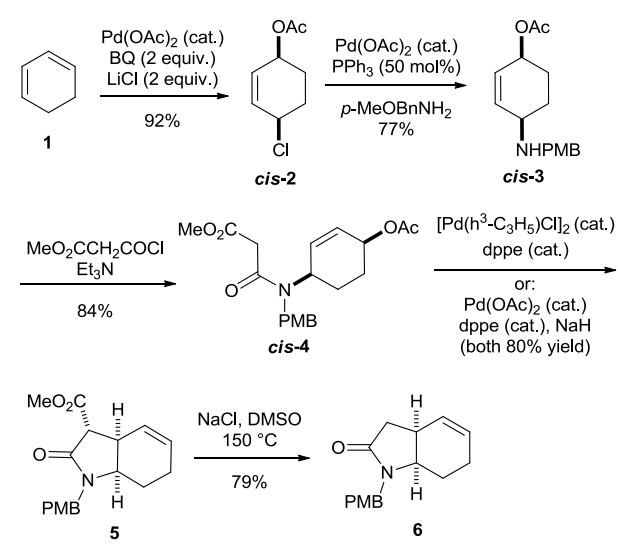

Scheme 2 Previous synthesis of the bicyclic tetrahydroindolone 6.

\section{Transformation of lactam 6 to the methoxycarbonylated} derivative 12.

Introduction of the carboxyl substituent at position 2 of the hexahydroindole bicycle was planned through $\alpha$-aminoether homologation. However, this type of strategy is viable only when the nitrogen atom of the aminoether function is electron poor. Accordingly, a PMB-to-Boc $N$-protection switch was accomplished through treatment with $\mathrm{CAN}$, followed by standard Boc protection of the resulting secondary amide 7. DIBAL-H reduction of $\mathbf{8}$ led to hemiaminal $\mathbf{9}$, whose treatment with $\mathrm{MeOH}$ in presence of a catalytic amount of $p-\mathrm{TsOH}$ gave the desired $N, O$-acetal $\mathbf{1 0}$ as a 3:1 diastereomeric mixture. C1-homologation was achieved through trimethylsilylcyanide (TMSCN) addition to $\mathbf{1 0}$ in the presence of $\mathrm{BF}_{3} \mathrm{Et}_{2} \mathrm{O}$. ${ }^{9}$ Finally, nitrile methanolysis ${ }^{10}$ $\left(\mathrm{K}_{2} \mathrm{CO}_{3}, \mathrm{MeOH}\right.$, rt; then $\left.7 \% \mathrm{HCl}\right)$ gave methyl ester 12 as an inseparable 1.5:1 diastereoisomeric mixture (Scheme 3). ${ }^{11}$

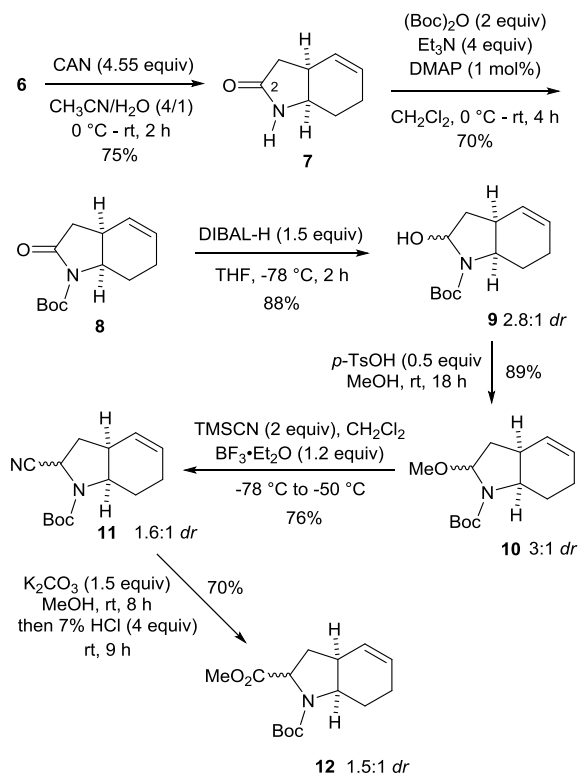

Scheme 3. Synthesis of the methoxycarbonylated derivative 12.

Different epimerization attempts, in the hope of obtaining a single (or at least highly prevalent) diastereoisomer of $\mathbf{1 2}$ were carried out. However, treatment of ester 12 with catalytic amount of DBU at room temperature or reflux (in the aim of reaching the thermodynamic regime), or treatment with a stoichiometric amount of a lithium amide (LDA or $\mathrm{LiNEt}_{2}$ ) followed by kinetic quenching, led only to recovered starting material with unchanged diastereoisomeric ratio, or degradation products. Furthermore, preliminary studies of epoxidation of intermediate 6 showed to be rather non-selective $(d r=1.3: 1){ }^{12}$ while epoxidation and dihydroxylation of diastereomeric mixtures of $\mathbf{1 1}(d r=1.6: 1)$ and $\mathbf{1 2}(d r=1.5: 1)$ under various conditions gave complex products/diastereomers. ${ }^{12}$

Judging that unsaturation at position 4,5 of the hexahydroindole bicycle was likely intrinsically unbiased for diastereoselective functionalizations, we passed to tackle an alternative way of generating this bicyclic unit, so as to obtain the unsaturation at position 6,7. This objective was achieved through a modified palladium-catalyzed strategy, featuring this time a domino sequence. ${ }^{13}$

Domino sequence-based approach to $N$-tosyl bicyclic tetrahydroindolone 17

This second strategy exploits the double Pd-catalyzed allylation of a malonamide with a cyclohexenyl bis-allylic system, according to a $\mathrm{C}$-allylation/ $\mathrm{N}$-allylation pseudo-domino ${ }^{14}$ sequence (Scheme 4). ${ }^{15}$ 


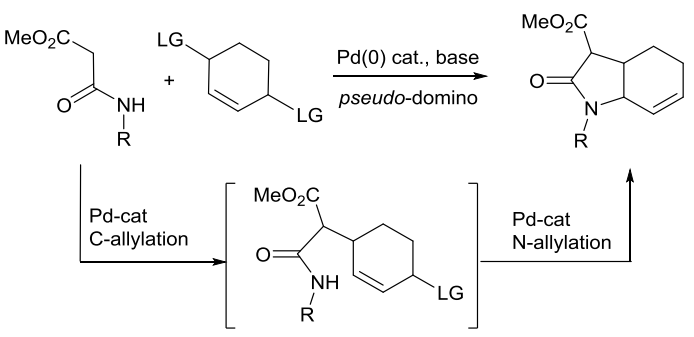

Scheme 4. Palladium-catalyzed $C$-allylation / $N$-allylation domino sequence.

$\mathrm{N}$-Tosyl malonamide $\mathbf{1 6}^{16}$ was selected as the appropriate $\mathrm{C} / \mathrm{N}$ double nucleophile, and its reaction with cis-OBz cyclohexene cis-14a using conditions similar to those adopted by Mori ${ }^{15}$ were first tested (Table 1). In particular, use of $\mathrm{NaH}$ (3 equiv.) as the base, gave the bicyclic product $17^{17}$ in $67 \%$ yield (Table 1 , entry 1). This result confirms that malonamides are effective $\mathrm{C} / \mathrm{N}$ bisnucleophiles for $\eta^{3}$-allyl palladium chemistry. Moreover, as the unsaturation in $\mathbf{1 7}$ is found at position 6,7 , it follows that the carbanionic site reacts before the nitrogen atom in the domino sequence. ${ }^{18}$ Other cyclohexenyl cis bis-allylic systems were then tested. Diacetate cis-14b gave the corresponding bicyclic product 17 in $52 \%$ yield (Table 1, entry 2), while the chloroacetate cis-2 intermediate smoothly led to $79 \%$ yield (Table 1 , entry 3 ).

Table 1. Palladium-catalyzed bis-allylation of the cis-OBz cyclohexene with $N$-tosyl malonamide. ${ }^{a}$

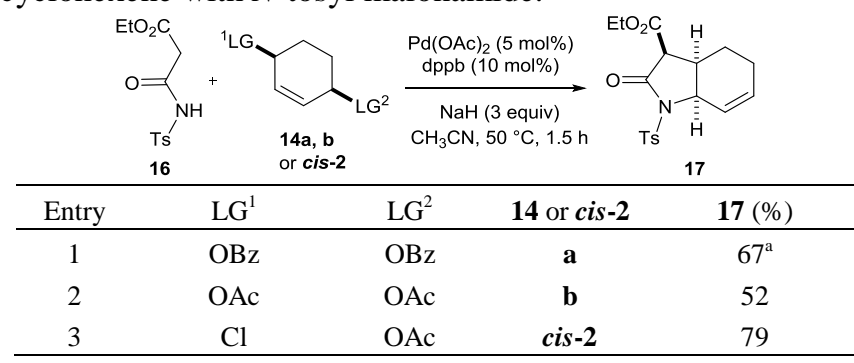

${ }^{a}$ Switch to $\mathrm{K}_{2} \mathrm{CO}_{3}$ (3.0 equiv.) afforded $45 \%$ yield of $\mathbf{1 7}$, while no product could be obtained without base.

Transformation of $N$-tosyl lactam 17 to the epimeric methoxycarbonylated derivatives 22 and 22'.

The 6,7-unsaturated bicyclic structure $\mathbf{1 7}$ was then processed in the same way as described previously for the 4,5-unsaturated one, so as to obtain the corresponding 2-methoxycarbonylated derivative. In this case, demethoxycarbonylation to give 18, followed by reduction to hemiaminal $\mathbf{1 9}$, formation of the $\mathrm{N}, \mathrm{O}$ acetal 20, and cyanide homologation afforded nitriles $\mathbf{2 1}$ and 21' in 4.5:1 ratio, which are easily separated by chromatography. Finally, separate acidic methanolysis of the two epimeric nitriles gave the two corresponding methyl esters 22 and 22. ${ }^{19}$ Gratifyingly, all the steps of this synthetic sequence turned out to be high yielding (Scheme 5).
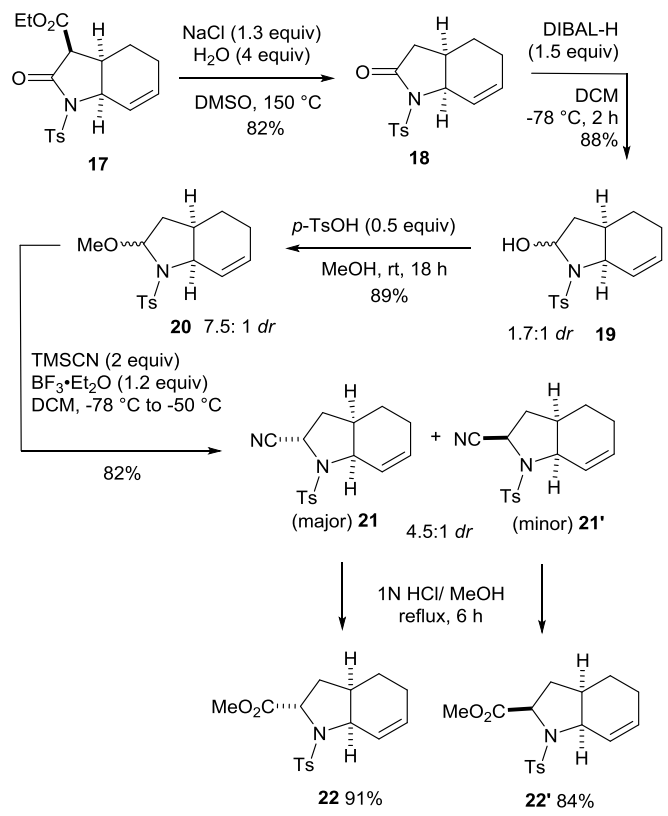

Scheme 5. Synthesis of the epimeric methoxycarbonylated derivatives 22 and 22'.

Stereoselective epoxidation and syn-dihydroxylation of 2methoxycarbonyl hexahydroindoles 22 and 22'

Then, standard epoxidation and syn-dihydroxylation of the two separated epimeric bicyclic structures 22 and 22' were tested. In the event, treatment of the major epimeric ester 22 with $m$-CPBA led to a 5:1 ratio of epoxydes $\mathbf{2 3 a}$ and $\mathbf{2 3 b}$, whereas under the same conditions the minor one $\mathbf{2 2}$ ' reacted in a totally stereoselective way, affording epoxyde $\mathbf{2 3}$ ' as a single isomer (Scheme 6, arrows in top right direction). Finally, separated syndihydroxylation of 22 and 22' with $\mathrm{OsCl}_{3}$ (cat.)/ $\mathrm{NMO}^{20}$ gave the two syn-dihydroxylated products $\mathbf{2 4}$ and $\mathbf{2 4}$ ' in good yields and interesting diastereoselectivities (Scheme 6, arrows in bottom right direction). The configurations of major diastereoisomers were confidently assigned via ${ }^{1} \mathrm{H}$ NMR NOESY and coupling constant analysis.
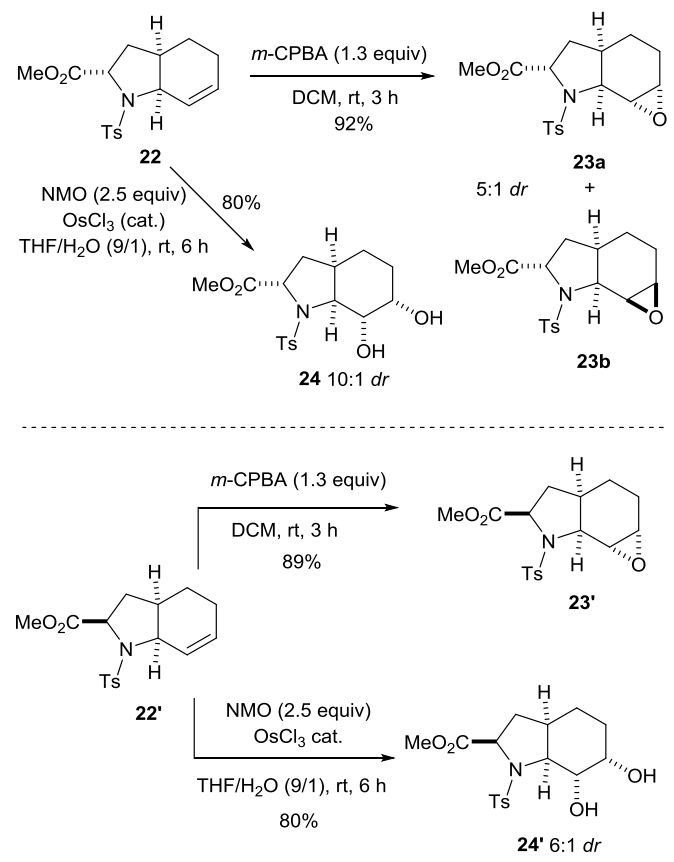

Scheme 6 Stereoselective epoxidation and syn-dihydroxylation of 2methoxycarbonyl hexahydroindoles 22 and 22'. 
The above results indicate that while the double bond in substrate 12 appears to be unbiased toward the tested electrophilic reagents, substrates $\mathbf{2 2}$ and 22' show a constant and strong preference to react through the least hindered face. Analysis of the substrates indicates that the allylic stereogenic centre of the cyclohexenyl ring, which is in close proximity to the reacting $\pi$-system, carries a tiny $\mathrm{CH}_{2}$ substituent in the case of $\mathbf{1 2}$, while that position is occupied by a bulky $N$-Ts moiety in the case of substrates 22 and 22'. The above difference, which in turn correlates with the conformational populations adopted by the respective substrates, may account for the dramatic selectivity difference shown by these two substrates (Figure 2).
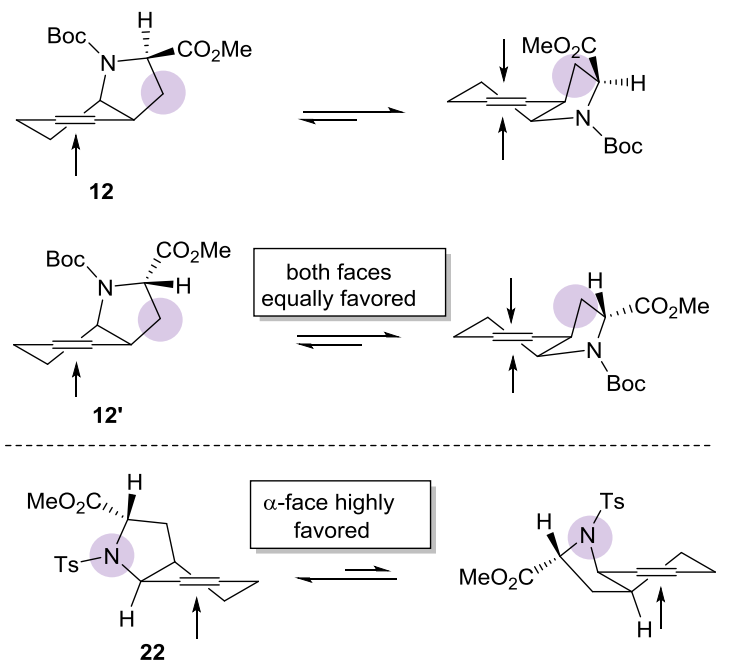

Figure 2. Comparison of selectivity of epoxidation and syndihydroxylation between substrates $\mathbf{1 2}$ and $\mathbf{2 2}$ (and 22') differing in the position of the unsaturation. The substituent of the allylic stereogenic centre is highlighted with a circle.

\section{Conclusions}

In summary, we have developed a synthetic sequence to reach analogues of the CHOI unit. The first steps of the synthetic sequence are a $C$-allylation and an $N$-allylation, both $\mathrm{Pd}$ catalyzed, which convert a cyclic bis-allylic substrate into a hexahydroindole structure. In particular, depending on the selected modus operandi - two separate steps versus a single pseudo-domino sequence - the unsaturation of the resulting hexahydroindole structures ends-up at different positions. After one-carbon homologation, epoxidation or syn-dihydroxylation of the resulting isomeric bicyclic advanced intermediates allowed to establish that unsaturation at 6,7 is more biased for diastereoselective electrophilic transformations to reach $\mathrm{CHOI}$ analogues. These results should be of relevance for future studies on aeruginosins synthesis and CHOI analogues.

\section{Acknowledgments}

We thank Omar Khaled for HRMS analyses. CNRS, UPMC and Labex Michem are acknowledged for financial support. Support through CMST COST Action, CA15106 (CHAOS) is also gratefully acknowledged. Z. M. thanks Erasmus Mundus Europe Asia (EMEA) organization for financial support.

\section{References and notes}

1. (a) Murakami, M.; Okita, Y.; Matsuda, H.; Okino, T.; Yamaguchi, K. Tetrahedron Lett. 1994, 35, 3129-3132; (b) Murakami, M.; Ishida, K.; Okino, T.; Okita, Y.; Matsuda, H.; Yamaguchi, K.; Tetrahedron Lett. 1995, 36, 2785-2788.

2. For a review, see: Ersmark, K.; Del Valle, J. R.; Hanessian, S. Angew. Chem. Int. Ed. 2008, 47, 1202-1223.
3. (a) Wipf, P.; Methot, J.-L. Org. Lett. 2000, 2, 4213-4216; (b) Valls, N.; Lopez-Canet, M.; Vallribera, M.; Bonjoch, J. Chem. Eur. J. 2001, 7, 3446-3460; (c) Ohshima, T.; Gnanadesikan, V.; Shibuguchi, T.; Fukuta, Y.; Nemoto, T.; Shibasaki, M. J. Am. Chem. Soc. 2003, 125, 11206-11207; (d) Valls, N.; Vallribera, M.; Carmeli, S.; Bonjoch, J. Org. Lett. 2003, 5, 447-450; (e) Hanessian, S.; Tremblay, M.; Petersen, J. F. W. J. Am. Chem. Soc. 2004, 126, 6064-6071; (f) Hanessian, S.; Wang, X.; Ersmark, K.; Del Valle, J. R.; Klegraf, E. Org. Lett. 2009, 11, 4232-4235 (Correction: Org. Lett. 2009, 11, 5566-5566); (g) Diethelm, S.; Schindler, C. S.; Carreira, E. M. Org. Lett. 2010, 12, 3950-3953; (h) Trost, B. M.; Kaneko, T.; Andersen, N. G.; Tappertzhofen, C.; Fahr, B. J. Am. Chem. Soc. 2012, 134, 18944-18947; (i) SofackKreutzer, J.; Martin, N.; Renaudat, A.; Jazzar, R.; Baudoin, O. Angew. Chem. Int. Ed. 2012, 51, 10399-10402; (j) Diethelm, S.; Schindler, C. S.; Carreira, E. M. Chem. Eur. J. 2014, 20, 60716080; (k) Dailler, D.; Danoun, G.; Ourri, B.; Baudoin, O. Chem. Eur. J. 2015, 21, 9370-9379; (1) Dailler, D.; Danoun, G.; Baudoin, O. Angew. Chem. Int. Ed. 2015, 54, 4919-4922; (m) Scherer, M.; Bezold, D.; Gademann, K. Angew. Chem. Int. Ed. 2016, 55, 94279431.

4. (a) Lemaire, S.; Prestat, G.; Giambastiani, G.; Madec, D.; Pacini, B.; Poli, G. J. Organomet. Chem. 2003, 687, 291-300; (b) Lemaire, S.; Giambastiani, G.; Prestat, G.; Poli, G. Eur. J. Org. Chem. 2004, 2840-2847.

5. For a review on cyclisations of allylic substrates via palladium catalysis, see: Hyland, C. Tetrahedron 2005, 61, 3457-3471.

6. (a) Bäckvall, J.-E.; Nyström J.-E.; Nordberg, R. J. Am. Chem. Soc. 1985, 107, 3676-3686; (b) Bäckvall, J.-E.; Vagberg, J. O. Org. Synth. 1990, 69, 38-43.

7. The coupling constant values in the ${ }^{1} \mathrm{H}$ NMR spectrum of the bicyclic products indicates the presence of a cis junction between the two rings, and a trans disposition between the ester function and the carbon atom of the 6-membered ring directly bound to the vicinal position. This assignment is in agreement with previous work by us and others. See: 4b; Ikeda, M.; Teranishi, H.; Nozaki K.; Ishibashi, H. J. Chem. Soc. Perkin Trans. 1 1998, 1691-1698.

8. (a) Krapcho, A. P. Synthesis 1982, 805-822; (b) Krapcho, A. P. Synthesis, 1982, 893-914.

9. The C1-homologation was also tested directly on the carbinolamine 10 with TMSCN in presence of boron trifluoride etherate. However, the desired cyano derivative $\mathbf{1 1}$ was obtained in low yield $(\sim 30 \%)$.

10. H. Norihiko, U. Toshiji, U. Hideki, Patent: Jpn. Kokai Tokkyo Koho, 25 Sep 2008, 2008222700.

11. Several nitrile methanolyses were tested before founding the satisfactory one. In particular, the system (TMSCl, $\mathrm{MeOH})$ and $(10 \mathrm{~N} \mathrm{NaOH}, \mathrm{MeOH})$ brought about simultaneous deprotection of the $N$-Boc protecting group and/or degradation.

12. Epoxidation of $\mathbf{6}$ with $m \mathrm{CPBA}$ produced an inseparable diastereomeric mixture in a 1.3:1 ratio with a combined yield of $83 \%$, while epoxidation or dihydroxylation of the diastereomeric mixtures of $\mathbf{1 1}$ and $\mathbf{1 2}$ yielded intractable mixtures of products or undistinguished diastereomeric mixture. For more details, see supporting information (S44-47).

13. (a) L. F. Tietze and G. Brasche, K. Gericke Domino Reactions in Organic Synthesis, Wiley-VCH, Weinheim 2006; (b) Tietze, L. F. Chem. Rev. 1996, 96, 115-136.

14. For a definition of pseudo and pure domino sequences see: (a) Poli, G.; Giambastiani, G. J. Org. Chem. 2002, 67, 9456-9459; (b) Prestat, G.; Poli, G. Chemtracts-Org. Chem. 2004, 17, 97.

15. For an analogous strategy see: Yochizaki, H.; Satoh, H.; Sato, Y.; Nukui, S.; Shibasaki, M.; Mori, M. J. Org. Chem. 1995, 60, 20162021.

16. For the synthesis of 16, see: Liu, Y.; Wang, X.; Xu, J.; Zhang, Q.; Zhao, Y.; Hu, Y. Tetrahedron 2011, 67, 6294-6299.

17. The coupling constant values in the ${ }^{1} \mathrm{H}$ NMR spectrum of the products suggest again the presence of a cis junction between the two rings. However, in this case a trans disposition between the ester function and the hydrogen atom of the junction is observed $\left(J_{\text {cis }}^{3} \approx 12 \mathrm{~Hz}\right.$ whereas $\left.J_{\text {trans }}^{3} \approx 7 \mathrm{~Hz}\right)$.

18. Unpublished experiments carried out in our laboratories indicate that the acidic carbon of these malonamides reacts constantly before the nitrogen atom in these domino sequences, irrespectively of the nature of the nitrogen protecting group, as well as of the equivalents of base used.

19. The relative stereochemistry of 21/21' and $\mathbf{2 2 / 2 2}$ ' were ascertained by ${ }^{1} \mathrm{H}$ NMR NOESY and coupling constant analysis, and compared with NMR structural analysis already described in 
literature for this kind of structure (ref. 3a,d). See also: Nuhrich A.

Moulines, J. Tetrahedron 1991, 47, 3075-3088.

20. Poli, G.; Scolastico, C. in Houben Weyl Methods of Organic Chemistry G. Helmchen, R. W. Hoffmann, J. Mulzer, E. Schaumann Eds; Georg Thieme Verlag: Stuttgart, New York, 1995; Chapter 4.4, Vol. E21, pp 4547-4598. 